\title{
Traffic accidents in childhood: prevention from the nurse's perspective
}

\section{Franciele Foschiera Camboin ${ }^{\mathrm{a}}$ \\ Beatriz Rosana Gonçalves de Oliveira Toso ${ }^{a}$ \\ Sebastião Caldeira ${ }^{a}$ \\ Marta Angélica lossi Silvab}

How to cite this article: Camboin FF, Toso BRGO, Caldeira S, Silva MAI. Traffic accidents in childhood: prevention from the nurse's perspective. Rev Gaúcha Enferm. 2021;42(spe):e20200171 doi: https://doi.org/10.1590/19831447.2021.20200171 aniversidade Estadual do Oeste do Paraná (UNIOESTE). Cascavel, Paraná, Brasil.

Universidade de São Paulo (USP), Escola de Enfermagem. Ribeirão Preto, São Paulo, Brasil.

\section{ABSTRACT}

Objective: to analyze the perception of nurses in primary health care on the prevention of traffic accidents with children as a component of care.

Method: study of a qualitative approach, with ten nurses from a municipality in Paraná. The data collected in 2017, through semistructured interviews, analyzed according to the modality of the inductive theme.

Results: two themes were identified: "prevention actions are secondary to cure"; "Indicating the way to prevent traffic accidents: nursing care". the reports explained that care usually occurs only after the accident, showing that preventive interventions are still insufficient. Intersectoral actions were identified as the path to care, with the school being especially recommended.

Conclusion: it was identified that the care in accident prevention is performed by the nurse, expanding the possibility of interaction and communication with the individual seeking the integrality and equity of health care.

Keywords: Nursing care. Child. Accidents prevention.

\section{RESUMO}

Objetivo: analisar a percepção dos enfermeiros da atenção primária a saúde sobre a prevenção dos acidentes de trânsito com crianças como componente do cuidado.

Método: estudo de abordagem qualitativa, com dez enfermeiros de um município do Paraná. Os dados foram coletados em 2017, por meio de entrevistas semiestruturadas, analisados segundo a modalidade da temática indutiva.

Resultados: identificou-se dois temas: "ações de prevenção são secundárias às de cura"; "indicando o caminho para a prevenção dos acidentes de trânsito: 0 cuidado de enfermagem". Os relatos explicitaram que 0 cuidado costuma acontecer somente após a ocorrência do acidente, evidenciando que intervenções preventivas ainda são insuficientes. As ações intersetoriais foram apontadas como caminho para o cuidado, sendo a escola especialmente recomendada.

Conclusion: identificou-se que o cuidado na prevenção dos acidentes é realizado pelo enfermeiro ampliando a possibilidade de interação e comunicação com o indivíduo buscando a integralidade e a equidade da atenção em saúde.

Palavras-chave: Nursing care. Criança. Prevenção de acidentes.

\section{RESUMEN}

Objetivo: analizar la percepción de las enfermeras en atención primaria de salud sobre la prevención de accidentes de tránsito con niños como un componente de la atención.

Método: estudio de un enfoque cualitativo, con diez enfermeras de un municipio de Paraná. Los datos recopilados en 2017, a través de entrevistas semiestructuradas, analizadas según la modalidad del tema inductivo.

Resultados: se identificaron dos temas: "las acciones de prevención son secundarias a la cura"; "Indicando la forma de prevenir accidentes de tráfico: cuidados de enfermería". Los informes explicaron que la atención generalmente se produce solo después del accidente, lo que demuestra que las intervenciones preventivas aún son insuficientes. Las acciones intersectoriales se identificaron como el camino hacia la atención, y se recomendó especialmente la escuela.

Conclusión: se identificó que la atención en prevención de accidentes la realiza la enfermera, ampliando la posibilidad de interacción y comunicación con el individuo que busca la integralidad y equidad de la atención médica.

Palabras clave: Atención de enfermería. Niño. Prevención de accidentes. 


\section{口INTRODUCTION}

Traffic accidents (TA) are the result of threats to a child's health and well-being, and human actions, or omissions that are preventable. Therefore, they arise from the negligence of those responsible, from the absence or lack of investment, inspection, legislation and efficient public control in traffic. Investments in sectors such as education and health are necessary in order to face this problem, especially in lowand middle-income developing countries ${ }^{(1-2)}$.

In addition to suffering and mourning, the financial loss caused by TAs is 1\% to $3 \%$ of gross domestic product in most countries ${ }^{(2)}$. Hospital expenses with TA can vary from 50 to 100 dollars per week for hospitalization caused by traumatic injury ${ }^{(3)}$. While the cost of investments in preventing the health of the poorest children is directly related to improving health outcomes, meaning each dollar invested results in twice as many protected lives, according to data from the United Nations for Children (UNICEF) ${ }^{(4)}$.

In this sense, the role of nurses in Primary Health Care (PHC) can play a unique role in child health prevention and promoting access to health care for vulnerable populations in urban areas $^{(5)}$. The same proposal the campaign launched this year, and entitled Nursing Now, which promotes the role and importance of nursing in the world. Especially considering the interfaces of intersectionality and interprofessionality, in addition to the integrality already mentioned.

We assume that the problem highlighted here, traffic accidents in childhood, needs to be addressed from the perspective of health promotion. However, it is understood that investing in the field of prevention of traffic accidents in childhood is needed, in order to subsidize health education practices, which impact on the reduction of deaths, disabilities and health costs generated by TA.

In this context, the problem has been little studied, and research that seeks to find out which activities can prevent accidents by generating safe behavior in traffic and saving lives is still rare or scarce. To this end, we seek to answer the following research question: How has prevention, focused on the care of traffic accidents involving children, been undertaken by PHC nurses?

Therefore, the objective of this research was to analyze the perception of PHC nurses on the prevention of traffic accidents involving children as a component of care.

\section{METHODOLOGY}

The conceptual framework of care used in this study is linked to the discussion of the integrality of health care, which establishes a dialogical relationship based on the valuation of the subjects, their experiences, knowledge, opinions and beliefs ${ }^{(6)}$.

Descriptive exploratory study, developed through a qualitative approach. Such proposal seeks to weave a common denominator in the speeches of the group of participants permeated by their concepts, experiences, meanings, beliefs and values. In this logic, it aims to understand the care for the TA phenomenon in childhood, with a focus on prevention, enriching and/or providing new observations on the objective data of reality ${ }^{(7)}$.

In this sense, the richness of details, the specifics and the sensitivity in the contradictions show the depth of the collected data. The answers to the initial questions about the phenomenon under study, from the perspective of the theoretical framework of care proposed by Ricardo Ayres ${ }^{(6)}$ guided the analysis of the participants'statements.

The study was developed in a medium-sized municipality located in the western region of the state of Paraná and integrates a larger doctoral study, of which, in this article, data from interviews with nurses are presented.

The first phase of the research occurred by identifying the data on TA victims in the database of the Fire Department/4th Fire Department, where the attendance of the TAs in the study municipality is recorded. Subsequently, we sought to identify data from emergency care units and hospitals where these victims were referred. Thus, information regarding the child's address was obtained and from there the health unit to which the household belonged was identified, as well as the nurses in these units.

Ten nurses took part in the research, according to the inclusion criteria, that is, after the identification of the 15 children (TA victims, aged between five and nine years). Two nurses refused to participate and in three other cases, the children attended the same health unit, meaning they were assisted by nurses who had already been interviewed. Therefore, there was no dropout during the research.

As an exclusion criterion, records for which there was no address and telephone number of the family of the child victim of TA in the medical record were considered, as well as occasions when the participant was released after pre-hospital care and the hospital lacked the access data of these persons. Health units that were not in the urban area were also excluded.

The interviews took place between May and August 2017. The first contact with nurses was made by telephone, with the appointment for data collection. The interviews were conducted individually, by the researcher, who has a nursing degree, a master's degree, and is properly trained to conduct 
data collection. The interviews took place in the workplace, chosen by the participants and at a time of their preference. The duration of the interviews ranged between 25 and 50 minutes, which were transcribed in full, by the same person, meaning the responsible researcher.

Repetitions in the reports were a criterion used to define the end of collection, allowing for a deeper understanding of the theme and the ability to reflect the totality of the phenomenon in its multiple dimensions, considering the trust and the internal validity of the study ${ }^{(8)}$.

The individual interviews were guided by a semi-structured script, in which the participants expressed their perceptions, experiences and meanings about the TAs with children in their area of coverage, what they have developed in attention to this event and regarding the existence of programs, intersectoral actions or activities specifically aimed at preventing TA.

The questions that guided the interview script were: How do you perceive accidents involving children in your area? What actions have you and your team taken to prevent and pay attention to traffic accidents involving children?

There was no need to repeat interviews, and after the transcripts returned to the participants for the necessary corrections and comments, they were finally organized according to the thematic analysis model.

Software R was used to organize the data coding and the package that was chosen for use was Qualitative Data Analyzes (RQDA) formulated by Universidad de la República (Uruguay) and Universidad Autónoma de Barcelona. This tool is directed towards systematizing data from qualitative analyzes, so the readings were performed by the researcher in charge, the selected and identified excerpts composing the first codes and following the thematic analysis phases, the themes were obtained ${ }^{(9)}$.

The themes or data patterns were recognized through inductive analysis in a coding process without trying to fit the data ${ }^{(10)}$. The analysis process went through five stages: (1) familiarization of the researcher with the data, (2) search for relevant data for the generation of initial codes, (3) the themes were developed/searched for, (4) the thematic map was generated, (5) it was permeated by an even greater refinement of the themes, and stage (6) writing the final report.

Following the theory that governs the thematic analysis technique, 32 codes were identified on the map, which generated the initial categories "Traffic accident is not emergent," "Inattention/(un)safe behavior in traffic," and "Care/educational practices in prevention of TA." Polishing the themes later generated the two categories presented in this text.
This research was approved by the Research Ethics Committee of the Ribeirão Preto School of Nursing at the University of São Paulo - EERP/USP, under approval number 1,761,748 and CAAE 57429316.0.0000.5393. All participants signed the Free and Informed Consent Form (FICF) in two copies, one for the researcher and one for the participant. To guarantee anonymity, the participants were represented by letters " $E$ ", following a numerical sequence as the interviews took place.

\section{RESULTS}

The ten participants in this study were aged between 29 and 53 years. The professional experience spanned between four and 30 years. Only two worked six hours a day. The rest worked eight hours.

Despite identifying that TA occurs in the areas of coverage in which they work, the nurse's statements evidenced the difficulty to carry out prevention and concerns for not performing such actions. Even so, they pointed out individual educational practices, in groups, even if elementary and envisioned alternatives for intervention in their speeches, articulating various sectors and actors showing their commitment with the population served.

The results configured a thematic map with 32 codes, elaborated according to the thematic analysis methods ${ }^{(10)}$. After verifying how the themes related to the codable extracts, it was possible to identify two themes: "Prevention actions are secondary to healing" and "Indicating the way to prevent traffic accidents: nursing care."

\section{Prevention actions are secondary to healing}

The reports of the present study illustrate the practice of care only after the event has elapsed and showed that the professionals find it difficult to perform TA prevention actions as an activity inherent to the nurse's role, with regard to the care to reduce a health problem. The following statements illustrate these observations:

He only comes to the unit for light problems [...] and sometimes we only know he came through the CHA [community health agent] who makes home visits or by other professionals. (E1)

Traffic accidents usually activate Samu [Mobile Emergency Service] or Siate [Integrated Service for Emergency Trauma Care] and are taken to UPAs [Emergency 
Care Units]. We only provide care to these patients after they are discharged, when they go to the health unit. (E4)

These two statements refer to the fragmented view of the health system, since it considers traffic accidents as not being a priority in primary care, but a factor to be addressed only in urgency and emergency.

It seems to illustrate the non-consolidation of the incorporation of the model proposed by the family health teams, meaning care is still centered on the biomedical paradigm, requiring curative actions, contrary to what would be expected for primary care, with a focus on health prevention and promotion, fostering the bond with its registered population, with individuals and community and the humanization of care.

We work with priority care, and even so, working with priorities, we can't handle it, and traffic accident don't enter the system as priorities [...]. Diseases are prevalent, so we leave prevention to the side to work with healing and that is so much pressure! (E5)

Another aspect that emanates from the statements is the observation that care in PHC focuses on spontaneous demand as a priority to the detriment of preventive actions.

The population's lack of clarity regarding the decentralization of the service network, the lack of information and difficulties in the issue of referral and counter-referral seem to influence the PHC's resolution power, as well as the nurse's autonomy when caring and welcoming.

After the accident, the patient comes to us [...]. He comes to get dressing for the wounds, to take medication. Sometimes we go to the person's house to dressing their wounds if they are bedridden for a period. Rehabilitation is at our discretion, our care. I think the health department should be involved in this. I think it's very important. (E6)

We end up with some demands that come from the Health Department and that usually have a response time, se we focus on that [the demands of the department]. I also think that we (those from primary care) are following a pattern that's been in place for some years. (E8)

When the community is less fortunate, as is our case, sometimes they don't have so much information. I don't even mean accidents; they just don't have much information to provide. Even their own rights, they lack knowledge to try and revindicate them and do something. (E6)
These statements seem to reveal that nurses still have a polarized view in the positivist, biomedical model, indicating the limitations in the search for effective responses to the health needs of individuals and complex populations to be considered at the moment when care is established.

\section{Indicating the way to prevent traffic accidents: nursing care}

The findings reveal that participants understand the intersectoral actions as a horizon for the provision of care. Schools are especially recommended in the speeches as a sector to be incorporated into the interventions.

Health education practices are part of a nurse's functions, seeking to mediate the development of children in a healthy way. The school environment is one of the main spaces for the implementation of health promotion programs and strategies, with a multi and intersectoral approach as the premise to ensuring children and adolescents survive today and in the future.

You'd need to check with the team to work with the groups, or in schools. To this day, I've never seen any unit work with traffic accidents, but I'm sure it could be explored in schools in the future. (E2)

In the HSP [Health at School Program] partnerships with DNIT [National Department of Transport Infrastructure] and CETRANS [State Traffic Council] improved the tracks, [...] and they have a project [...], to raise awareness in the municipal school that focuses on children between four and ten years of age, because we see mothers picking up the children in CEMEIS [Municipal Centers for Early Childhood Education], but not at school. And many six or four-year-old children walk home alone, or with their older brother. (E3)

I can develop individual educational practices during my visits, which is the part that I advise, for example, for pregnant women, when they go for prenatal care, during postpartum care I can mostly guide mothers, as a preventive measure I can also give guidance, and regarding traffic accidents [...] (E4)

We can start at schools, because we are able to cover the three categories. We manage to catch parents, children, educators and health, because the traffic accident directly involves health. Prevention happens there. (E6)

The whole team can do the waiting room, and they do. And we also address several issues, notices in general. 
And we also talk about traffic [...]. We would have to set a day and that day people would be invited. (E7)

In general, parents and society do not know that general causes are the main causes of infant mortality and that this issue should be better addressed. We know that the school is a very strategic place for us to work with this age group, with this audience, we might actually develop intersectoral actions. (E8)

There are neighborhood associations, schools, children's pastoral care, but work is currently a little segregated. In general, the Department of Health may be promoting accident prevention in children and adolescents in the children's area, which is highly demanded by academics [...]. (E9)

In my opinion, what I can work on starts with Bolsa Familia, which in my opinion is the age group that is to be guided and where the mothers are too. (E10)

However, some individual or isolated educational practices are presented as actions already carried out, as is the case of campaigns that are carried out on time, which seems to be the logic of actions guided by demand, by campaigns or educational practices that are still isolated.

\section{DISCUSSION}

Worldwide, more than 500 children under the age of 18 die each day on the roads, and thousands more are injured ${ }^{(1)}$. Physical, psychological, social sequelae and the time they are away from school activities or health rehabilitation are also aspects that imply the vulnerability of these subjects. It is considered that children are more exposed, as they have difficulty in facing and judging situations of danger, proximity, speed, direction, sounds. These specificities in growth and development make them dependent on parents, family members, caregivers, society and the government, and they are often predisposed to accidents, defenseless and vulnerable to violence ${ }^{(11)}$.

The reports identify that the technical dimension of care goes beyond, in addition to educational activities, due to the various activities of nurses in PHC, such as the application of vaccines, dressing, checking vital signs, among others. These expressions indicate that nurses participating in this study understand care as an action when performing a procedure during a direct encounter of the individual to be cared for. They also show the possibility of starting a therapeutic relationship between the health professional and the individual. They identify care in a technical procedure, expanding the possibility of interaction and communication with the individual who seeks health services.

Care, therefore, can be understood from three conceptual perspectives: as an ontological, genealogical and reconstructive category, in the perspective proposed by Ayres ${ }^{(6)}$. In this way, it comprises the articulation between biomedical sciences, human sciences and epidemiology, proposing preventive measures and more assertive definitions through fruitful therapeutic interactions between subjects. In view of this, it seeks to remedy the problem identified or made explicit by the patient, since the health professional strives to achieve well-being as the purpose of this interaction.

Thus, care as an ontological category, which influences the nurse's care practice, is marked by the following elements: "Movement, interaction, identity/otherness, plasticity, project, desire, temporality, non-causality and responsibility"(6:50).

It opposes the polarized, fragmented mechanistic care practice that favors technical procedures influenced by the hegemonic medical-curative model, still evident in the nursing routine. Technological advances have also contributed to a care centered on curative actions, thus, discussion on how care has been taking place in the Brazilian health system is encouraged ${ }^{(12)}$.

The technologies available in the biomedical area often make professionals limit their actions to the realization of techniques. In this sense, it is worth reviewing the practices, because when performed in isolation they are insufficient and ineffective, showing numerous health problems and hospitalizations that could have been avoided in PHC. It is necessary to turn to effective care ${ }^{(6)}$, in which the other is actively present and the interactions are fertile and agile. In this way, permeated by the light technologies used rationally, expanding horizons and, therefore, seeking health interventions articulated with other areas of knowledge. This point of view may not be the simple one, but it is an action to be taken for integral health practice.

In this sense, the statements show that the care provided by nurses participating in the study is still linked to technical actions aimed at curative actions and work overload, corroborating other studies, pointing to the challenge expected in the context of PHC, guided by comprehensive care ${ }^{(5)}$.

It can be inferred that there is a close relationship between the increased service demand and the understanding of the condition studied here. Not just that, but the health problem and the consequent lack of prioritization of care surrounding it. Studies confirm the fact that overwork, the need to reach goals and a reduced team can lead to the choice of activities at the expense of others ${ }^{(5,13)}$. Even so, the care for the prevention of TA can be the leader in preventative and 
health promotion actions, in view of the autonomy and competence of nurses in PHC.

The idea of following standards, that is, continuously following the same behaviors, reminds us of the possibility of resistance to changes. In this sense, traditions, work routine and daily habits end up culturally and/or organizationally, whether individual or social. Linked to this observation, it is necessary to highlight the role of nurses in PHC in the promotion, prevention and adequate health control ${ }^{(14)}$. Therefore, in the planning and design of health actions that articulate the participation of interprofessional teams and services, performing significant routines in which collective work intervenes in the real health risks of the population served.

The educational practices carried out by nurses are developed in a programmed manner with specific groups ${ }^{(13)}$ corroborating the data evidenced in this study, in which the nurse prioritizes care under the curative logic, but when overcome, it can promote emancipatory educational processes based on the integral model and humanized care.

The nurse often performs health education actions on an individual basis. They are: childcare, prenatal care, home visits, post-discharge guidance, and are key parts in coping and protecting the child from traffic accidents. However, in order to expand and give sustainability to this performance, it could be carried out in association with a set of strategies, sectors and actors that need to incorporate, perform and promote safe behavior throughout their surroundings ${ }^{(15)}$.

Economic inequalities point to the poor distribution of the countless benefits of today's society. In other words, to face threats to children's health and well-being, a deliberately multisectoral approach is required, with massive investment in the education and health sectors ${ }^{(1)}$.

Knowing and applying intervention strategies for the prevention of TA has been the objective of studies, which has found, in its results, that the behavior of children and adolescents tends to be influenced by the example of their caregivers or companions. This behavior also happens in relation to traffic ${ }^{(16-17)}$. Thus, performing isolated activities has not been an efficient strategy. However, multifaceted interventions with the participation of schools and the school community will certainly contribute to the promotion of safe behavior for children in traffic in a global manner.

Multidimensional educational practices ${ }^{(1,15)}$ have been developed seeking to reduce injuries caused by TA. Thus, these interlocutions of knowledge and the association of multifaceted actions have resulted in successful experiences involving children, families, communities, educators and other caregivers in these practices.
When understanding education through the aspect of dialogicity, health professionals understand man as a conscious body. Educational practices integrate the capacities and skills of citizens, with the information transmission being a process that is constantly changing. In this way, they comprise a teaching-learning process, governed by dialog, promoting a fertile field for emancipation and participation of subjects, preparing them to intervene in society ${ }^{(18)}$.

When considering the TAs in this proposal, educational practices become a stimulus for critical reflection on health conditions, the causes and consequences of this disease in particular. They make it possible to mobilize the participation of individuals, popular groups, the health team to overcome the adversities that keep them vulnerable, collectively proposing resolutions to overcome or minimize these situations of children's exposure.

In no way are health prevention and promotion actions limited to educational practices containing technical information and transmitted from the professional to the subject. Therefore, it is necessary to identify the needs jointly and build responses to the needs in a dialogical way.

Another point to be considered is the need, pointed out in the statements of some nurses, to perform actions in conjunction with schools. In this perspective, the Ministry of Health's Health at School Program (HSP) ${ }^{(19)}$ stands out, which is based on the surveillance and prevention of accidents and violence, on promoting school health and on the culture of peace, but which seems to not address accident prevention.

Despite the fact that prevention is indispensable in this context of the study, multiprofessional practice is an alternative to organize health work. Interdisciplinary care and collaborative practices are measures that contribute to directing various views towards the individual in an attempt to promote comprehensive care ${ }^{(12)}$. Therefore, each professional stands out in their expertise, but in isolation, it is not enough ${ }^{(20)}$.

Thus, the TA prevention activities carried out by nursing, involve not only the care provided after the TA, but actions that prevent them from happening. That is, whenever the opportunity to intervene is observed. With a view to improving the conditions of the injured individual, as well as other individuals involved, such as family, friends, co-workers, community.

Nursing may be important in the advancement of PHC, particularly in health promotion, disease prevention and care, especially with vulnerable populations ${ }^{(14)}$. TAs involving children in low- and middle-income countries, as is the case in Brazil, happen when children start to perform activities 
independently. Such as: going to school alone, for example, or when they become economically active and most vulnerable. In this perspective, expenses with rehabilitation and the effects on the victim and the family can be extremely harmful and cyclical, especially in the long term ${ }^{(3)}$.

The safe behavior of road users and the reduction in traffic-related deaths depend on more than knowledge and skills. They also depend on community support, the perception of vulnerabilities and risks, social rules and models, engineering measures and monitoring law compliance ${ }^{(2,12)}$. Therefore, in addition to nursing care, programmed actions need to be developed, such as effective public policies, legislation, inspection and traffic engineering actions that permeate the complexity of the TA phenomenon, seeking comprehensive child care.

The study deals with a theme that is scarcely explored in the field of professional nursing practice. The results presented can contribute to the nursing care practice in PHC, as it highlights the need to expand and carry out the work of preventing TAs in an articulated and intersectoral way, consolidating a comprehensive health care model.

Thus, the study may foster new paradigms based on health promotion, overcoming the hegemonic hospital-centered and medical-curative model and prioritizing nursing care. This nursing care that is established in the action, attitude and daily movement of the team and services when considering the presence of the other in the assistance space.

In addition, it considers an interdisciplinary and intersectoral perspective in the optimization and diversification of forms and quality of interaction, in the enrichment of the horizons of knowledge and actions in health ${ }^{(7)}$. Highlighted, the leading role of nurses working in PHC, given their place, role and performance with the health teams.

In this perspective, the current challenge is to articulate explanation and understanding in the interpretation of the TA phenomenon. In addition to statistical data that are influenced by cause and effect factors, the proposal to analyze the care directed to children for the prevention of TAs, also considering social, programmatic factors and even non-scientific knowledge, is intended to overcome vulnerabilities.

When attempting to implement this articulation, there is an approximation of a normative plan, meaning there is the possibility of choosing a more appropriate care and action plan, unique for each context and subjects, different from reductionist care, which does not dialog with other areas of knowledge or does not consider practical knowledge and the life context of the population served.

It is necessary for prevention as a form of care to be the target of research and dialogs in PHC, in an attempt to understand the role of nurses and their care practices, as well as the meanings they attribute to such practices, seeking visibility in the national scenario and incorporating them into traffic accident prevention actions.

\section{FINAL CONSIDERATIONS}

The initial assumption of the study was confirmed. The prevention of traffic accidents as a nursing care has been carried out timidly in activities that are not well articulated. It is emphasized that care in preventing accidents must be undertaken simultaneously with the search for interventions that promote equality and equity of the population.

In the view of the nurses in this study, multifaceted and multidisciplinary educational practices are indicated as a fundamental plan to articulate fields of knowledge, community and state in the intervention to reduce the problems studied here.

In addition to the objective being achieved, the study advanced in order to highlight care as a part in reducing traffic accidents, as an activity inherent to the nurse's role and pointing out the intersectoral actions as a horizon for the realization of this care.

This research indicates the importance of expanding studies on prevention as nursing care, considering that primary health care is the privileged space to develop health prevention actions, corroborating the prerogative of the Nursing Now Campaign, to promote the adequate visibility of Nursing, which works incessantly in actions to improve vital indicators.

In this sense, health promotion and prevention strategies for comprehensive care are supported by the work of the health team, especially nurses, allowing the articulation between prevention and care as an interdisciplinary and intersectoral collaborative practice.

As a contribution, the articulation between different areas of knowledge may show an option for a more assertive care plan, that is, for singular care or actions, according to the needs of each subject and reality, responding to the paradigm of comprehensive care and the true encounter between users and professionals. 


\section{REFERENCES}

1. Clark H, Coll-Seck AM, Banerjee A, Peterson S, Dalglish SL, Ameratunga S, et al. A future for the world's children? a WHO-UNICEF-Lancet Commission. The Lancet. 2020 Fev;395(10224):605-58. doi: https://doi.org/10.1016/ S0140-6736(19)32540-1

2. World Health Organization (CH). Save lives: a road safety technical package. Geneva: WHO; 2017 [cited 2020 Jul 10]. Available from: https://apps. who.int/iris/bitstream/handle/10665/255199/9789241511704-eng. pdf? sequence $=1$

3. United Nations Children's Fund, Foundation for the Automobile and Society. Rights of way: child poverty \& road traffic injury in the SDGS. New York: FIA Foundation, Unicef; 2016 [cited 2020 Jul 10]. Available from: https://www. fiafoundation.org/media/391038/rights-of-way-spreads.pdf

4. United Nation Children's Fund (US). Narrowing the gaps: the power of investing in the poorest children. New York: Unicef; 2017 [cited 2020 Jul 10]. Available from: https://www.unicef.org/publications/files/UNICEF_The_power_of_ investing_in_the_poorest_children.pdf

5. World Health Organization (CH). State of the world's nursing 2020: investing in education, jobs and leadership. Geneva: WHO; 2020 [cited 2020 Jul 10]. Available from: https://www.who.int/publications/i/item/9789240003279

6. Ayres JRCM. Care: work, interaction and knowing health practices [editorial]. Rev Baiana Enferm. 2017 [cited 2020 Jul 10];31(1):e21847. Available from: https://portalseer.ufba.br/index.php/enfermagem/article/view/21847/14172

7. Silva Filho OC, Minayo MCS, Costa AP. Técnicas que fazem uso da palavra, do olhar e da empatia: pesquisa qualitativa em ação. Aveiro: Ludomedia. 2019 [Resenha]. Ciênc Saúde Coletiva. 2020;25(5):1991-2. doi: https://doi. org/10.1590/1413-81232020255.22042019

8. Minayo MCS. Amostragem e saturação em pesquisa qualitativa: consensos e controvérsias. Rev Pesqui Qualitat. 2017 [cited 2020 Jul 10];5(7):1-12. Available from: https://edisciplinas.usp.br/pluginfile.php/4111455/mod_resource/ content/1/Minayosaturacao.pdf

9. The R Project for Statistical Computing [Internet]. Vienna: The R Foundation; 2020 [cited 2020 May 06]. Available from: https://www.r-project.org/

10. Braun V, Clarke V, Hayfield N, Terry G. Thematic analysis. In: Liamputtong P. (eds) Handbook of research methods in health social sciences. Singapore: Springer; 2019. p. 843-60. Available from: https://doi. org/10.1007/978-981-10-5251-4_103
11. Nunes AJ, Sales MCV. Violence against children in Brazilian scenery. Ciênc Saúde Coletiva. 2016 Mar;21(3):871-80. doi: https://doi. org/10.1590/1413-81232015213.08182014

12. Hämel K, Toso BRGO, Casanova A, Giovanella L. Advanced practice nursing in primary health care in the Spanish National Health System. Ciênc Saúde Coletiva. 2020 Jan;25(1):303-14. doi: https://doi. org/10.1590/1413-81232020251.28332019

13. Vera MG, Merighi MAB, Conz CA, Silva MH, Jesus MCP, González LAM. Primary health care: the experience of nurses. Rev Bras Enferm. 2018;71(Suppl 1):531-7. doi: https://doi.org/10.1590/0034-7167-2016-0244

14. Organização Pan-Americana da Saúde (US). Ampliação do papel dos enfermeiros na atenção primária à saúde. Washington, DC: OPAS; 2018 [cited 2020 Jul 10]. Available from: https://iris.paho.org/bitstream/ handle/10665.2/34960/9789275720035_por.pdf?sequence $=6$

15. Will KE, Dunaway KE. Evaluation of a participative education process for increasing tween restraint use in Virginia: The Make it Click initiative. Transport Res Part F: Traffic Psychol Behav. 2017 Feb;45:54-64. doi: https://doi. org/10.1016/j.trf.2016.11.013

16. Kovess-Masfety V, Sowa D, Keyes K, Husky M, Fermanian C, Bitfoi A, et al. The association between car accident fatalities and children's fears: a study in seven EU countries. PLoS ONE. 2017 Aug;12(8):e0181619. doi: https://doi. org/10.1371/journal.pone.0181619

17. Holm A, Jaani J, Eensoo D, Piksoeoet J. Pedestrian behaviour of 6th grade Estonian students: implications of social factors and accident-prevention education at school. Transport Res Part F: Traffic Psychol Behav. 2018;52:112-9. doi: https://doi.org/10.1016/j.trf.2017.11.005

18. Silva JP, Gonçalves MFC, Andrade LS, Monteiro EMLM, Silva MAI. Health promotion in primary education: perceptions of bachelor's degree with a teaching diploma in nursing students. Rev Gaúcha Enferm. 2018;39:e20170237. doi: https://doi.org/10.1590/1983-1447.2018.2017-0237

19. Ministério da Saúde (BR). Portaria interministerial no 1.055, de 25 de abril de 2017. Redefine as regras e os critérios para adesão ao Programa Saúde na Escola - PSE por estados, Distrito Federal e municípios e dispõe sobre o respectivo incentivo financeiro para custeio de ações. Brasília, DF; 2017 [cited 2020 Jul 10]. Avaialble from: http://bvsms.saude.gov.br/bvs/saudelegis/gm/2017/ pri1055_26_04_2017.html

20. Lukewich JA, Tranmer JE, Kirkland MC, Walsh AJ. Exploring the utility of the Nursing Role Effectiveness Model in evaluating nursing contributions in primary health care: a scoping review. Nursing0pen. 2019;6(3):685-97. doi: https://doi. org/10.1002/nop2.281 
- Financing:

The project was carried out with the support of the Higher Education Personnel Improvement Coordination - Brasil (CAPES, or Coordenação de Aperfeiçoamento de Pessoal de Nível Superior - Brasil) - Financing code 001 and the Araucaria Foundation - Support for the scientific and technological development of Paraná (Fundação Araucária).

Support of the Conselho Nacional de Desenvolvimento Científico e Tecnológico /CNPq - Research Productivity Process: 305469/2019-3.

\section{- Authorship contribution:}

Franciele Foschiera Camboin: Concept, data curation, formal analysis, financing prospection, investigation, methodology, software resources, writing - original draft, writing - review and editing.

Beatriz Rosana Gonçalves de Oliveira Toso: Concept, methodology, written visualization - original draft, writing - review and editing.

Sebastião Caldeira: Methodology, written visualization review and editing.

Marta Angélica lossi Silva: Concept, data curation, formal analysis, financing prospection, methodology, project management, resources, supervision, writing, written visualization - review and editing.

\section{- Corresponding author:}

Franciele Foschiera Camboin

E-mail:smfran@hotmail.com.br

\section{Associate editor:}

Dagmar Elaine Kaiser 